\title{
Research of rolling of engines of bridge-type agricultural tools on the trace of a constant technological track
}

\author{
Adamchuk V. ${ }^{1}$, Bulgakov V. ${ }^{2}$, Kuvachov V. ${ }^{3}$, Holovach I. ${ }^{4}$ Ihnatiev Ye. ${ }^{5}$ \\ ${ }^{1} \mathrm{NSC}$ «Institute of Mechanization and Electrification of Agriculture» \\ 11 Vokzalna Str., Hlevakha township, Vasylkiv district, Kyiv oblast, 08631, Ukraine \\ ${ }^{2,}{ }^{4}$ National University of Life and Environmental Sciences of Ukraine \\ 15 Heroiv Oborony Str., Kyiv, 03041, Ukraine \\ 3, 5 Tavria State Agrotechnological University named after Dmytro Motornyi \\ 18 B. Khmelnytskoho Ave., Melitopol, Zaporizhzhia oblast, 72312, Ukraine e-mail: \\ 1vvadamchuk@gmail.com, ${ }^{2}$ vbulgakov@meta.ua, ${ }^{3}$ kuvachoff@ukr.net, ${ }^{4}$ holovach.iv@gmail.com, \\ ${ }^{5}$ yevhen.ihnatiev@tsatu.edu.ua \\ ORCID: ${ }^{1}$ 0000-0003-0358-7946, ${ }^{20000-0003-3445-3721, ~}{ }^{3} 0000-0002-5762-256 X,{ }^{4} 0000-0003-1387-4789$, \\ ${ }^{5} 0000-0003-0315-1595$
}

Goal. To study the correlation between the indicators of physicomechanical properties of the soil trace of the constant technological track and their influence on the traction properties of the bridge agricultural tool. Methods. Experimental studies were conducted according to generally accepted and developed methods and involved the use of modern control and measuring equipment. Results. As the dimensionless criterion for assessing the rolling of the wheel of a specialized wide-track agricultural tool, taking into account its tangential force and resistance, the coefficient fk of its rolling resistance is taken in the work. Based on experimental researches and processing of the received data on the personal computer analytical expressions of regressive dependences of the coefficient of rolling resistance of wheels on humidity, hardness, and density of a trace of a constant technological track are created and their graphic charts are constructed. The results of experimental studies have shown that the physicomechanical properties of the soil in the traces of a constant technological track and the coefficient of rolling resistance of agricultural tools have a fairly high correlation. Conclusions. As a result of the carried out researches, it is established that the physicomechanical properties of a soil trace of a constant technological track essentially influence energy expenses on overcoming forces of resistance to the rolling of wheels of agricultural tools. With an increase in the soil of moisture of the permanent technological track from 10 to $45 \%$, the coefficient of rolling resistance increases from 0.06 to $0.1(66 \%)$. And since the charges of power to overcome the forces of resistance during motion are proportional to the value of $\mathrm{fk}$, the same percentage increases in energy consumption. With increasing hardness from 2.8 to $4.5 \mathrm{MPa}$ and density from 1.3 to $1.6 \mathrm{~g} \cdot \mathrm{cm}-3$ of the soil trace, the rolling resistance coefficient of the wheels of the agricultural tool decreases from 0.1 to 0.06 . Also, with the increase in the hardness of the soil trace of the constant technological track from 2.5 to 4.0 $\mathrm{MPa}$, the value of the coefficient of volumetric crushing of the soil - from 4.0 to $45.0 \mathrm{MPa}$. With the further increase in the hardness of the soil trace, the coefficient of volumetric shrinkage of the soil almost does not increase. To reduce the coefficient of rolling resistance of the wheels when moving on the ground track of a constant technological track, it is necessary to form it as an undeformed bearing surface, then the rolling resistance has the least value.

Key words: traction properties, monitoring of properties, density, hardness, rolling resistance, experimental researches.

$$
\text { DOI: https://doi.org/10.31073/agrovisnyk202010-07 }
$$

Modern world agricultural production is characterized by a qualitatively new stage of technical reequipment. International scientific publications increasingly publish information on the efficiency and prospects of using bridge tractors (or bridge agricultural equipment) [1-4]. Their appearance makes it possible to solve the fundamental contradiction in the "engine-soil" system, the essence of which is that to achieve high traction and coupling properties of the energy means its engines must contact the leveled and solid support surface. And for the normal growth of cultivated plants requires a fluffy structured environment with optimal density and humidity. In practice, such requirements can be met only when a clear distinction is made in the field of the zone of movement of bridge agricultural unit (technological zone of the field) and the zone of plant growth (agrotechnical zone of the field) [5, 6].

The movement of bridge agricultural equipment in the footsteps of a constant technological track provides better traction and traction properties compared to a traditional tractor moving on an agricultural background [7]. The nominal traction force developed by the bridge tractor under the condition of sufficient adhesion of its propulsion to the bearing surface of the traces of a constant technological track should naturally be greater than that of a traditional tractor, with the same technical parameters. At the same time, the coupling of the engines of the bridge agricultural unit with the bearing surface of the traces of the constant technological track should be sufficient for it to be able to develop the nominal traction force when 
working with a certain level of towing. At the same time, it is known from the classical theory of the tractor that the small value of the slip corresponds to a smaller value of the tangential force of traction, which it develops.

Conditions of movement of the bridge agricultural unit on a firm leveled basic surface of traces of a constant technological track should realize in the agricultural tool the maximum tangential force of draft. While for a traditional tractor the maximum value of this force falls on the slip, which significantly exceeds the level at which unacceptable destruction of the soil environment is possible [8]. Hence the need to find the following compromise: the maximum slippage of the wheeled mover of a bridge agricultural unit must be such that, provided it has sufficient traction on the supporting surface of the tramline tracks, it develops the maximum possible tangential traction force.

One of the main tasks to be solved in the rolling theory of the driving wheel of a specialized widetrack agricultural unit is to improve the quality of its grip on the bearing surface of the tracks of a constant tramline to ensure maximum traction force. In this case, the grip of the driving wheel of a wide-track agricultural unit with the supporting surface of the tracks of a constant tramline is determined by the action of such forces: the friction forces between the ground and the supporting surfaces of the tire, the gearing forces occurring at the tire ground hooks on the ground, the forces acting in the plane of the ground bar cut, located between the ground hooks [7].

With the increase in the mechanical strength of the ground track of a constant technological track increases the adhesion force of the wheel of agricultural unit with the supporting surface of its rolling. In this case, the wheel of wide gauge agricultural unit realizes higher torque and maximum traction force. At high density of the ground bearing surface, the friction force between the ground and the bearing surfaces of the agricultural unit tire has a significant influence on the formation of adhesion, and therefore on the traction. If the density of the soil track of a constant tramline decreases, the depth of penetration of the wheel of an agricultural unit tire by the ground hooks increases. In this case, the traction is more influenced by the forces of ground hooks wheel hitch and friction in the plane of the ground bar cut, located between the ground hooks [7].

Analytical studies carried out by us have shown that the rolling resistance force of the wheels of agricultural unit depends on the properties of the soil track of a constant tramline, which is characterized by the coefficient of volume buckling [9]. This factor is closely correlated with soil hardness.

So, one of the most important conditions for sufficient grip of the wheels of the specialized widetrack agricultural unit with the supporting surface and their minimum rolling resistance is the physical and mechanical properties of the traces of a constant technological track. Monitoring of its properties is a real basis for ensuring a high coefficient of efficiency of the work of specialized wide-track agricultural units.

Analysis of recent research and publications. The correlation between soil density and hardness has been sufficiently studied by scientific research and practical experience [10,11]. At the same time, it is known that the hardness of the soil is affected not only by its density, but also moisture, which is unevenly distributed both on the surface of the field and the depth of the soil [8].

But the physical and mechanical properties of the soil in the conditions of an agricultural agrophone essentially differ from properties of the condensed leveled trace of a constant technological track. And this does not allow the use of known analytical relationships that link the above indicators. There is practically no information about the experimental evaluation of the properties of soil traces of a constant technological track in the track system of agriculture, in particular, when using specialized wide-track agricultural units when moving on it. The beginning of such research is given in [13]. In this work, on the basis of experimental researches, graphs of regression dependences of density and hardness of soil traces of a constant technological track on their humidity are constructed. An analytical and on its basis a graphical regression dependence of the density of the soil trace of the constant technological track on its hardness is also obtained. Therefore, research in the direction of monitoring the properties of the constant technological track and the impact of these properties on the rolling process of the wheel of the bridge agricultural unit is not enough, which determines the relevance of these studies.

The purpose of research - study of the correlation between the indicators of physical and mechanical properties of the soil trace of a constant technological track and their influence on the traction and coupling properties of a specialized wide-track agricultural unit.

Materials and methods. Experimental studies were conducted on a prototype of a bridge agricultural unit, the general view of which is presented in Fig. 1. This agricultural tool has a wheel drive with pneumatic tires size 9.5R32. 


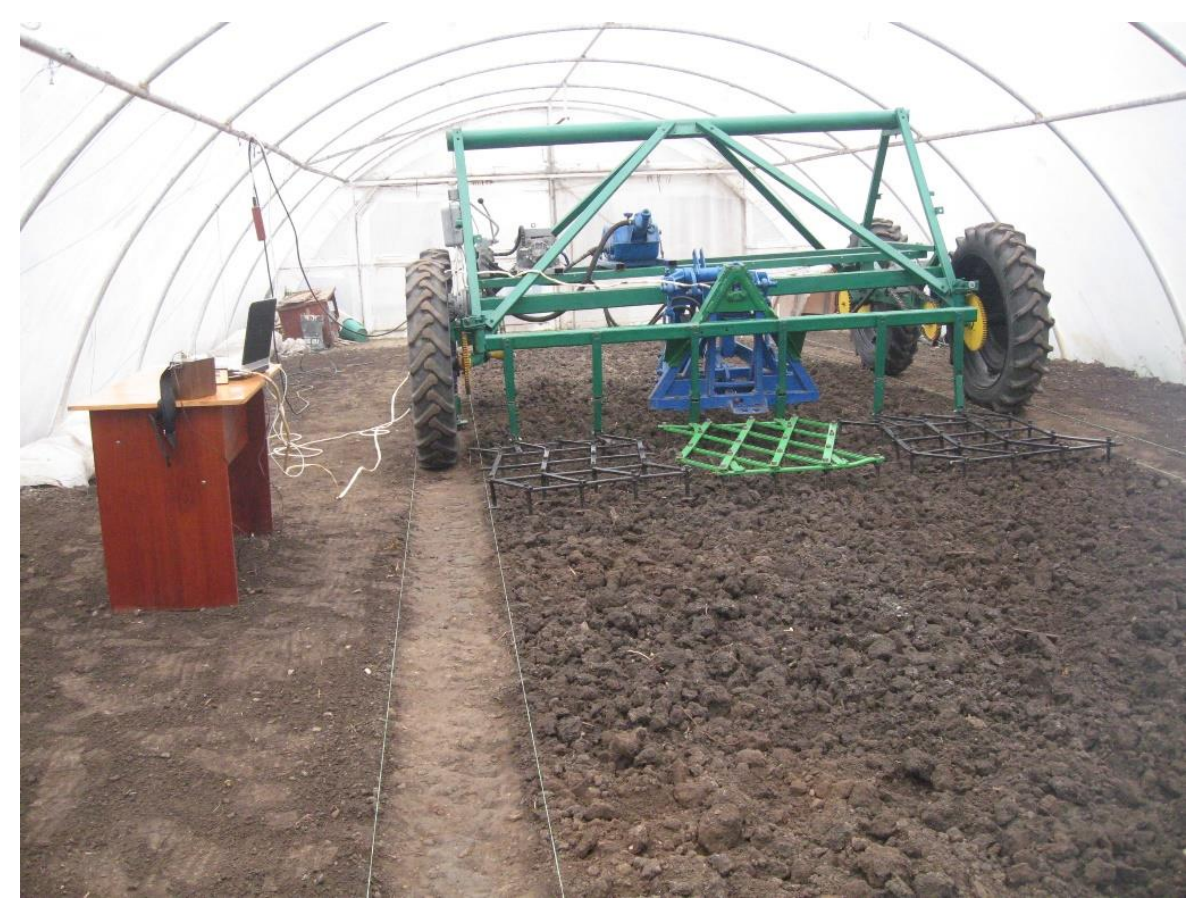

Fig. 1. Bridge agricultural unit during researches in the soil channel moving on soil traces of a constant technological track

The physical and mechanical properties of soil traces of a constant tramline were measured in the thickness of the layer $0 \ldots 5 \mathrm{~cm}$, agrophone $-0 \ldots 15 \mathrm{~cm}$. For determination of soil hardness the hardness meter of Revyakin system was used. Density of the soil traces of tramline and agrophone was measured with density meter, and moisture - with moisture meter MG-44. In order to minimize the error of determining the indicators of physical and mechanical properties of the soil traces of a constant tramline and agrophone experiments were conducted in multiple repetitions. The obtained values of these indicators were further averaged. Error of direct experimental measurement of parameters by the specified devices did not exceed $2 \%$.

In the process of experimental studies the rolling resistance force of the wheel of agricultural unit was determined by the principle of "free" its movement on the supporting surface. The specified "free movement" of wide-track agricultural unit on the trail of a constant technological track was carried out by its forced movement with the help of a traction mechanism (Fig. 2).

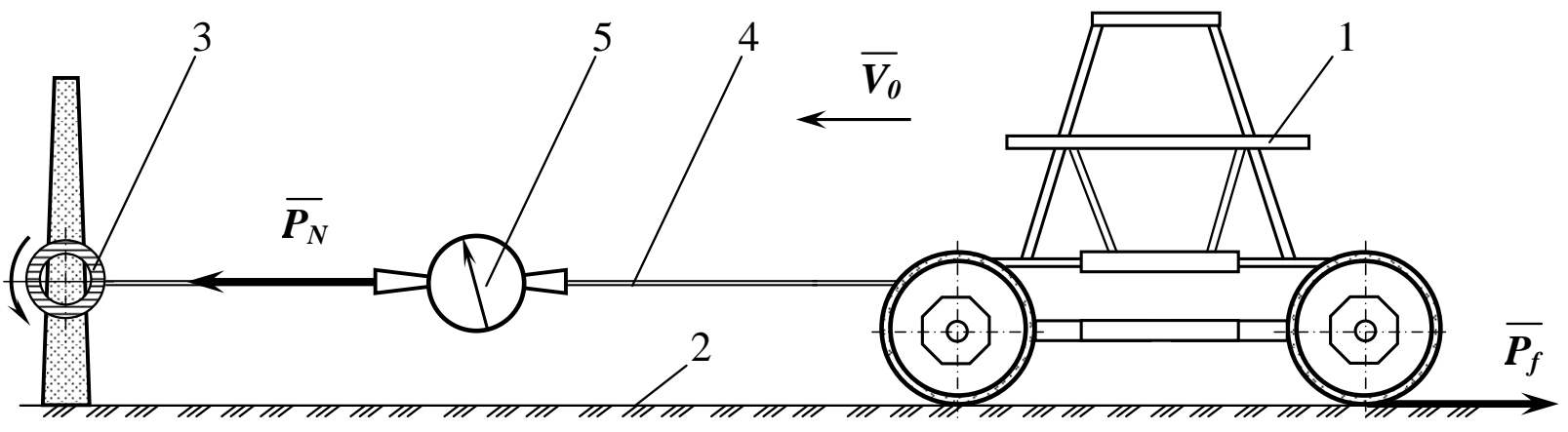

Fig. 2. Laboratory complex for determining the rolling resistance of the agricultural unit on the trail of a constant technological track

The laboratory complex (Fig. 2) consisted of agricultural unit 1 , the wheels of which were freely rolled over the formed track 2 of the constant technological track. Free movement of agricultural unit 1 on track 2 of constant technological track was carried out by means of traction mechanism 3 , the cable 4 of which was attached to it. The value of effort, which was applied for the free movement of agricultural unit 1 on the trail 2 of the constant technological track, was fixed on the scale of the dynamometer 5.

The basis for the laboratory determination of the rolling resistance of the agricultural unit in the wake of a constant technological track is the equality of the resistance to its rolling $P_{f}$ and effort $P_{N}$ according to the indications of the dynamometric device with which its free rolling was carried out (fig. 2). 
Research results. As rolling of the wheel of agricultural unit with elastic rim on the soil track of permanent technological track is characterized by energy consumption to overcome rolling resistance forces, revealing of interrelation of its parameters and rolling conditions, search of criteria of wheel rolling process estimation as well as determination of ways to reduce rolling resistance are the main tasks to be solved in studying of this process. Thus it is necessary to notice that dependence of the coefficient of resistance to rolling of a wheel of wide-track agricultural units on physical and mechanical properties of a soil supporting surface of a constant technological track on which it moves, in particular, from its humidity, density and hardness, are considered and investigated by scientists insufficiently. However, as shown by the results of studies, such a movement of specialized agricultural unit in the track system of agriculture is characterized by lower energy consumption.

According to the dimensionless criterion of wheel rolling estimation of the specialized wide gauge agricultural unit, taking into account its tangential force and resistance, the rolling support coefficient $f_{k}$ is adopted.

When considering the rolling process of a wheel of a specialized broad gauge agricultural unit on the soil track of a constant technological track, the factors accompanying the work of its wheels in the general case were excluded: irregular movement, lifting or lowering, bearing resistance in the wheel hub, the resistance of the air environment. The research is based on the fact that the wheel of a specialized wide gauge agricultural unit with a constant air pressure in its tire rolls along the following horizontal section of a constant tramline at an even speed.

The results of experimental studies have shown that the physical and mechanical properties of the soil in the traces of a constant technological track and the coefficient of resistance to rolling of wheels of wide gauge agricultural unit have a rather significant correlation relation. For example, the nature of the influence of soil moisture in the traces of a constant technological track on the rolling resistance coefficient of wheels of agricultural unit is presented in Fig. 3. . From the analysis of the graph shown in this figure, it follows that with increasing soil moisture in the traces of a constant technological track increases the rolling resistance coefficient of the broad gauge agricultural unit.

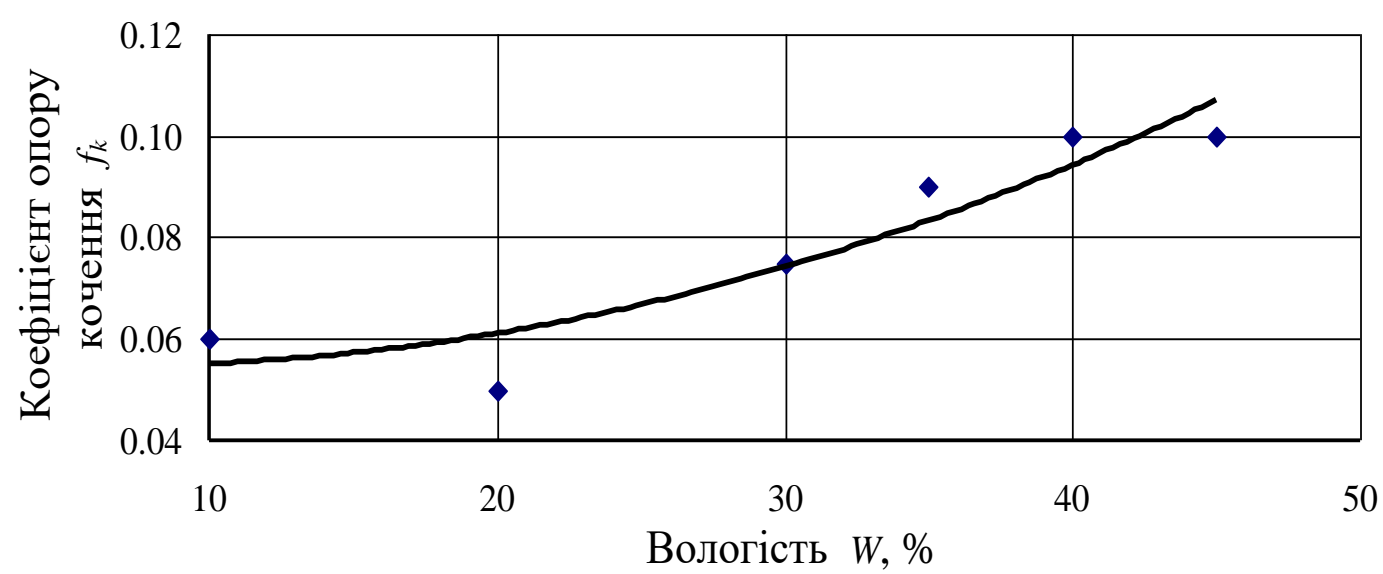

Fig. 3. Dependence of the rolling resistance coefficient $f_{k}$ of agricultural unit from moisture $W$ of the soil trace of a constant technological track

As a result of the conducted experimental researches it is established that with increase of humidity of a soil trace of a constant technological track from 10 to $45 \%$ the coefficient of resistance to rolling of wheels of agricultural units increases from 0,06 to 0,1 . In percentage terms, this is $66 \%$. And since the power consumption of a wide-track agricultural unit to overcome the rolling resistance of its wheels when moving is proportional to the value $f_{k}$, then energy consumption increases by the same percentage.

Explain the obtained nature of the relationship between the indicators presented in Fig. 3 , it is possible that with the increase in the moisture content of the soil trace of the constant technological track increases the energy consumption for crushing the soil when moving on it a broad-track agricultural unit. These costs are increased by an increase in the area of contact between the tyre and the supporting surface and by an increase in the depth of the track formed by pushing the wheel through the soil track. As a result, the rolling resistance coefficient of the wheels of a wide gauge agricultural unit increases as well, because the energy consumption for soil deformation in this case significantly exceeds the energy consumption for deformation of the bean tire itself.

Dependence between the resistance coefficient $f_{k}$ to rolling of a wide-track agricultural unit and humidity of a soil trace is precisely enough approximated by an expression of such kind: 


$$
f_{k}=4 \cdot 10^{-5} \cdot W^{2}-5 \cdot 10^{-4} \cdot W+0,0562,
$$

where $W$ - humidity of the top layer of soil in the traces of a constant technological track, \%.

The accuracy of the obtained analytical expression (1) can be estimated by the value of the correlation coefficient of the relationship, the square of the value of which is $R^{2}=0,8767$. The high value of the latter indicates the possibility of practical use of the obtained analytical dependence (1) in estimating energy losses on rolling wheels of specialized wide-track agricultural unit on the soil track of a constant technological track, taking into account its humidity.

Since soil moisture in the traces of a constant technological track naturally affects its hardness and density, so their change also affects the change in the rolling resistance coefficient $f_{k}$ of the agricultural unit (Fig. 4 and Fig. 5).

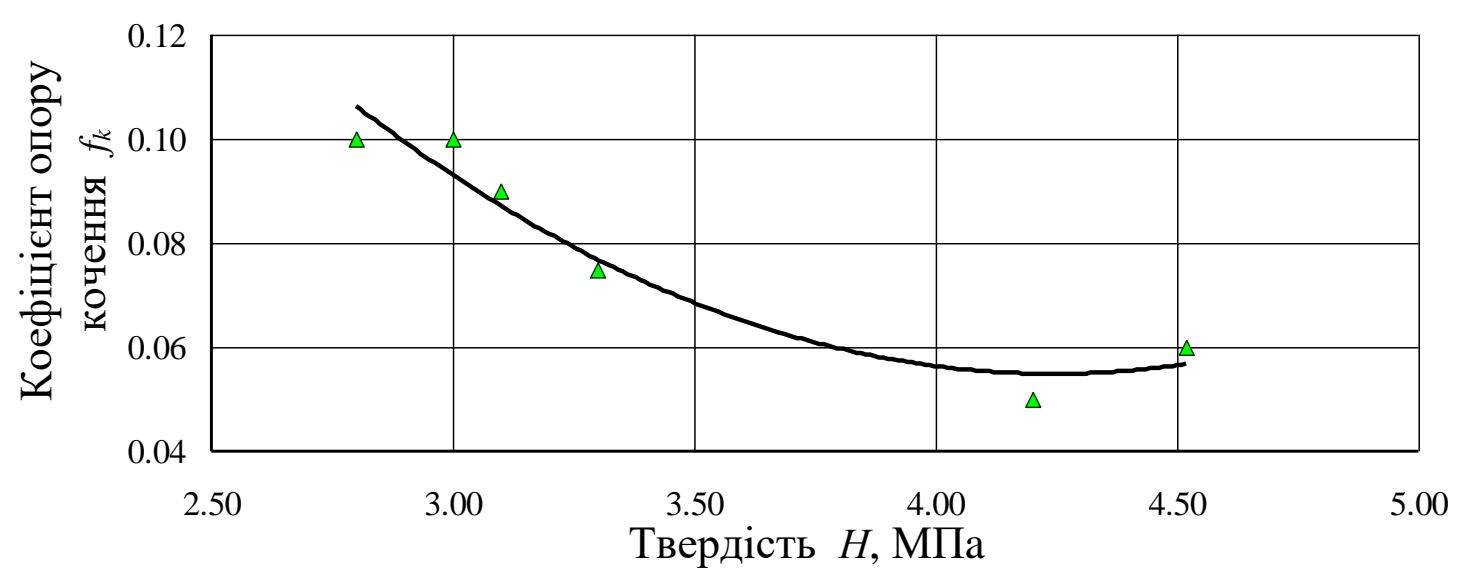

Fig. 4. Dependence of the resistance coefficient $f_{\mathrm{k}}$ to rolling of wheels of agricultural units from hardness $H$ of a soil trace of a constant technological track

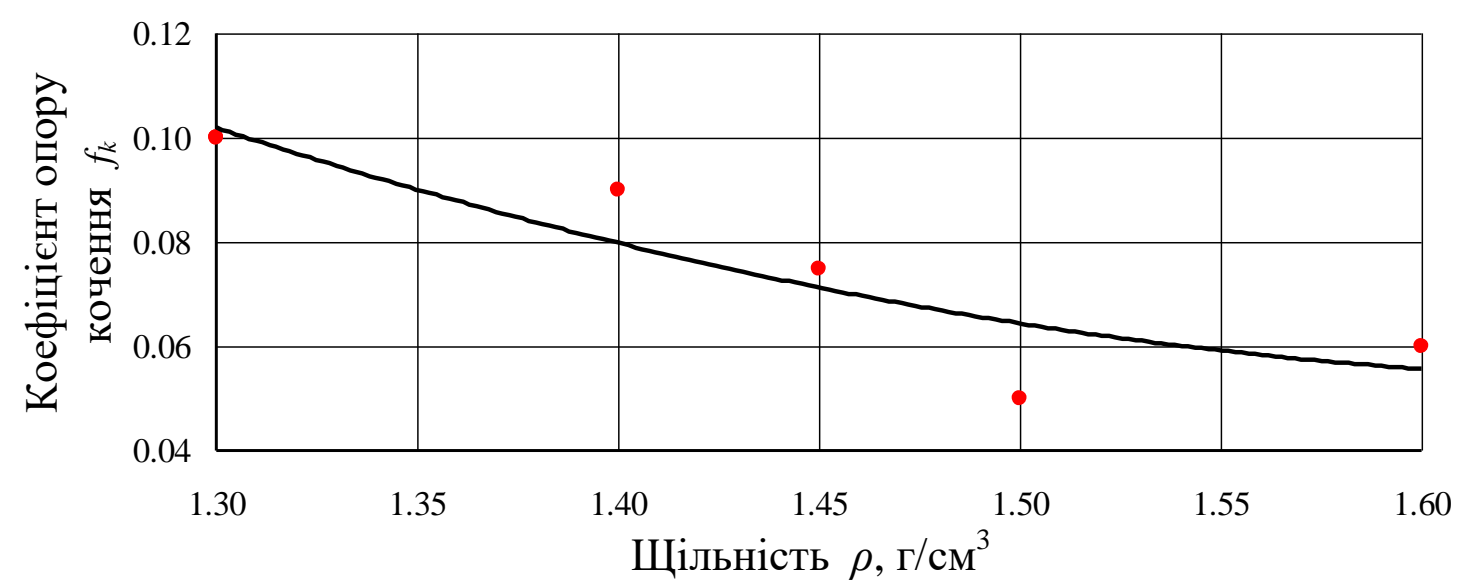

Fig. 5. Dependence of the resistance coefficient $f_{k}$ to rolling of wheels of agricultural units from density $\rho$ of a soil trace of a constant technological track

Analysis of the experimentally obtained dependences presented in Fig. 4 and fig. 5, showed that with increasing hardness $H$ and density $\rho$ of a soil trace of the constant technological track decreases the resistance coefficient $f_{\mathrm{k}}$ to rolling of wheels of agricultural means at its movement on it. This reduction is quadratic, so it is quite accurately described by quadratic dependences of this kind:

$$
f_{k}=0,0247 \cdot H^{2}-0,2093 \cdot H+0,499,
$$

where $H$ - soil hardness in the traces of a constant technological track, determined by the Revyakin system, MPa,

$$
f_{k}=0,335 \cdot \rho^{2}-1,1256 \cdot \rho+0,9991,
$$


where $\rho$ - soil density in the traces of a constant technological track, $\mathrm{g} \cdot \mathrm{cm}^{-3}$.

It should be noted that the correlation between the hardness of the soil trace of the constant technological track with the rolling resistance coefficient $f_{k}(2)$ is stronger than the connection between the density of the soil trace and it (3). The square of the correlation coefficient of the hardness of the soil trace of a constant technological track with $f_{k}$ equal $R^{2}=0,9395$, and density $-R^{2}=0,8419$.

Explain the nature of the dependencies obtained experimentally, as shown in the figure. Fig. 4 and Fig. 5 , it is possible that the increase in the hardness and density of the soil track of a constant technological track contributes to the reduction of energy consumption transmitted to the wheel of an agricultural unit, to perform such works as vertical buckling of the soil and the formation of a compacted trail, as well as the friction of the tire tread on the supporting surface in the contact zone. Therefore, in order to reduce the ratio $f_{k}$ when moving a wide-track agricultural unit along the soil track of a constant technological track, it is necessary to strive to form it, practically, as a non-deformed surface. When rolling the wheel of a specialized agricultural unit on such a solid and dense support surface, the rolling resistance of its wheel is the smallest.

On the basis of the aforesaid it follows that the rolling resistance coefficient of a wheel of a specialized broad gauge agricultural unit on a soil track of a constant technological track can be estimated accurately enough on the size of its hardness. It allows to establish interrelation of parameters of the wheel of agricultural unit, physical and mechanical properties of a soil track of a constant technological track with indicators of trace formation. For this purpose we take advantage of dependence Granvuane-Horyachkin [8] on definition of size of factor of resistance to rolling:

$$
f_{k}=0,86 \cdot\left[\frac{G_{N}}{k_{r} \cdot b_{0} \cdot D_{0}^{2}}\right]^{\frac{1}{3}},
$$

where $k_{r}$ - the coefficient of volumetric crushing of the soil, $\mathrm{H} \cdot \mathrm{m}^{-3} ; D_{0}, b_{0}$ - static diameter and width of the wheel tire, respectively, $m$.

We equate the dependences (2) and (4). As a result, we get:

$$
0,86 \cdot\left[\frac{G_{N}}{k_{r} \cdot b_{0} \cdot D_{0}^{2}}\right]^{\frac{1}{3}}=0,0247 \cdot H^{2}-0,2093 \cdot H+0,499 .
$$
the soil:

From the obtained equation (5) we determine the value of the coefficient of volumetric crushing of

$$
k_{r}=\frac{0,636 \cdot G_{N}}{b_{0} \cdot D_{0}^{2} \cdot\left(0,0247 H^{2}-0,2093 H+0,499\right)^{3}} .
$$

Substituting the values of the parameters $D_{0}$ and $b_{0}$ of the tires $9.5 \mathrm{R} 32$ of agricultural unit, as well as the value of the normal vertical load $G_{N}$, acting on its wheel, in expression (6), an analytical dependence is obtained, which establishes a relationship between the coefficient $k_{r}$ of volumetric crushing of the soil in the traces of a constant technological track with its hardness $H$ (fig. 6).

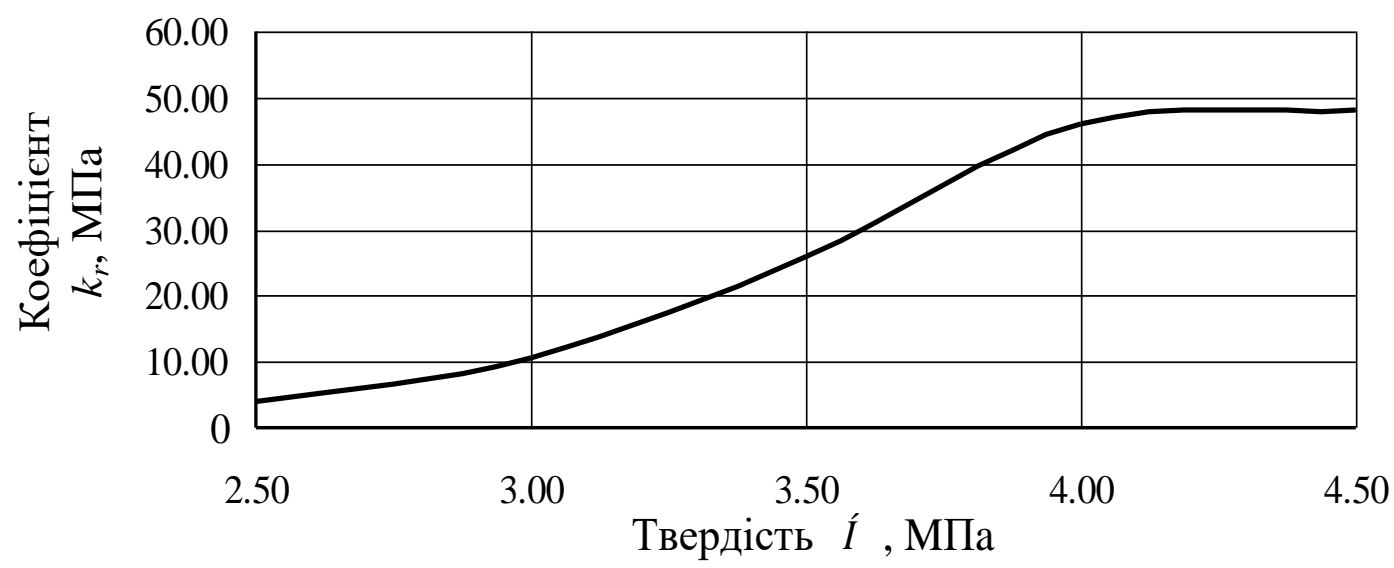

Fig. 6. Dependence of the coefficient $k_{r}$ volumetric crushing of the soil from hardness $H$ of trace of a constant technological track 
From the analysis of the graphical dependence shown in Fig. 6, it follows that with increasing the hardness of the soil trace of the constant technological track from 2.5 to $4.0 \mathrm{MPa}$, the value of the coefficient of volumetric crushing of the soil, namely from 4.0 to $45.0 \mathrm{MPa}$, also increases intensively. With a further increase in the hardness of the soil trace of the constant technological track, the increase in the coefficient of volumetric crushing of the soil is practically not observed.

The graphical dependence presented in fig. 6 , is very convenient for indirect analytical estimation $k_{r}$ in terms of hardness $H$ of a soil trace of a constant technological track. Because the method of determining the coefficient of volumetric crushing of the soil is somewhat more complicated than determining its hardness.

On the basis of the results of the conducted research we have established that the indirect estimation of rolling resistance coefficients of wheels of agricultural unit on the traces of a constant technological track and volume buckling of soil on the size of its hardness is accurate enough. It allows, if necessary, to define the specified parameters in an analytical way (according to the dependencies (2) and (6)) by the experimentally measured value of only the hardness of the soil track of the constant technological track.

\section{Conclusions}

As a result of the conducted researches it is established that physical and mechanical properties of a soil track of a constant technological track essentially influence energy expenses on overcoming of forces of resistance to rolling of wheels of a specialized wide gauge agricultural unit. With increase in humidity of a soil track of a constant technological track from 10 to $45 \%$ the coefficient of resistance to rolling of its wheels increases from 0,06 to 0,1 that makes $66 \%$. And as expenses of power of wide-track agrofoil on overcoming of forces of resistance to rolling of its wheels at movement are proportional to value of $f_{k}$, then energy consumption increases by the same percentage.

With increasing hardness from 2.8 to $4.5 \mathrm{MPa}$ and density from 1.3 to $1.6 \mathrm{~g} \cdot \mathrm{cm}^{-3}$ of a soil trace of a constant technological track the coefficient of rolling resistance of wheels of an agricultural tool at movement on it decreases from 0,1 to 0,06. In this case, the correlation between the hardness of the soil trace of the constant technological track with the coefficient of rolling resistance of the agricultural unit is stronger $\left(R^{2}=0,9395\right)$, than the relationship of the density of the soil trace with it $\left(R^{2}=0,8419\right)$. This allows you to accurately and analytically determine the specified rolling performance of the wheel of a specialized wide-track agricultural unit and power consumption for rolling when moving on the soil track of a constant technological track, as well as indicators of trace formation analytically by experimentally measured value of soil track hardness.

With increase of hardness of soil track of constant technological track from 2,5 to 4,0 MPa the value of coefficient of volume crushing of soil also increases intensively, namely from 4,0 to 45,0 MPa. At further increase of hardness of a soil track of a constant technological track the increase of factor of volume crushing of soil practically is not observed.

In order to reduce the rolling resistance coefficient of wheels of the specialized broad gauge agricultural unit at its movement on the soil track of a constant technological track it is necessary to strive to form it as a deformed supporting surface. When rolling a wheel of an agricultural unit on such a hard and dense supporting surface the rolling resistance of the wheel of an agricultural unit has at least the following value.

\section{References}

1. Onal, I. (2012). Controlled traffic farming and wide span tractors. Agricultural Machinery Science, 8 (4), 353-364.

2. Pedersen, H.H., Oudshoorn, F.W., \& McPhee, J.E. (2016). Wide span - re-mechanising vegetable production. XXIX International horticultural congress on horticulture: sustaining lives, livelihoods and landscapes: international symposia on the physiology of perennial fruit crops and production systems and mechanisation, precision horticulture and robotics Book Series: Acta Horticulturae, 1130, 551557.

3. Bulgakov, V., Adamchuk, V., Kuvachov, V. et al. (2018). Study of effectiveness of controlled traffic farming system and wide span self-propelled gantry-type machine]. Research in Agricultural Engineering, 64(1), 1-7.

4. Chamen, W.C.T. (20-22 March 2000). A new methodology for weed control and cereal crop production based on wide span vehicles and precision guidance (pp. 51-55). Biotrac. Processing 4th EWRS workshop on physical weed control Netherlands.

5. Nadykto, V. (2011). Koliina tekhnolohiia zemlerobstva [Track technology of agriculture]. Farmer, 1, 22-23. [in Ukrainian].

6. Nadykto V.T., Hoichuk A.F., \& Kiurchev V.M. (2006). Perspektyvy vprovadzhennia koliinoi systemy zemlerobstva na Ukraini [Prospects for the implementation of the track system of agriculture in Ukraine]. Scientific Bulletin of NAU, 92, 38-43. [in Ukrainian]. 
7. Bulgakov, V., Kuvachov, V., Ivanovs, S. et al. (2020). Research of properties of constant technological track of a bridge-type field machine. (pp. 26-33). TECHNOFORUM 2020 «New Trends in Machinery and Technologies for Biosystems».

8. Kutkov, G.M. (2015). Traktory i avtomobili: teoriya i tekhnologicheskie svoystva [Tractors and cars: theory and technological properties]. A textbook. Moscow: NIC INFRA. [in Russian].

9. Kuvachov, V.P. (2011). Analiz metodyk vyznachennia hlybyny tekhnolohichnoi kolii dlia vypadku yii prokladannia na grunti kolesamy enerhozasobu. [Analysis of methods for determining the depth of the technological track for the case of its laying on the ground by the wheels of the power tool]. Works of TSATU, 11(1), 96-103. [in Ukrainian].

10. Vasiliev, S.I. (2007). Sovershenstvovanie metodiki i tekhnicheskikh sredstv gorizontalnogo izmereniya tverdosti pochvy s vnedreniem tekhnologii koordinatnogo zemledeliya [Improvement of methods and technical means of horizontal measurement of soil hardness with the introduction of coordinate farming technology]. Author's ref. dis. Cand. tech. Science: 05.20.01. Penza. [in Russian].

11. Bulgakov, V., Kuvachov, V., \& Olt, J. (23-26th October 2019, Zadar, Croatia). Theoretical study on power performance of agricultural gantry systems. (pp. 0167-0175). Proceedings 30th DAAAM International symposium «Intelligent manufacturing and automation». DAAAM International. Vienna, Austria.

12. Adamchuk, V.V., Bulgakov, V.M., Kuvachov, V.P., Holovach, I.V., Ihnatiev, Ye.I., \& Chernysh, O.M. (2020). Doslidzhennia vlastyvostei postiinoi tekhnolohichnoi kolii, yaku vykorystovuiut pry mostovomu zemlerobstvi [Research of properties of a constant technological track which is used at bridge agriculture]. Bulletin of Agricultural Science, 8, 62-68. doi: 10.31073/agrovisnyk202008-08 [in Ukrainian]. 